\title{
Ergonomic Risk Factors for Low Back Pain among Three-Wheel Drivers in Ethiopia: A Community-Based Cross-Sectional Study
}

\author{
Yonas Biratu Terfa ${ }^{D},{ }^{1}$ Adugna Olani Akuma, Ebissa Bayana Kebede, ${ }^{1}$ Abdisa Eba Tucho, ${ }^{1}$ \\ Birhanu Abdisa, ${ }^{3}$ Selam Ayele, ${ }^{1}$ Mestawet Getachew Enbakom, ${ }^{4}$ Fikadu Balcha Hailu $\mathbb{D}^{\mathbb{D}}{ }^{1}$ \\ and Gugsa Nemera Germossa ${ }^{1}$
}

\author{
${ }^{1}$ School of Nursing, Institute of Health, Jimma University, Jimma, Ethiopia \\ ${ }^{2}$ Department of Nursing, Wollega University, Institute of Health Sciences, Nekemte, Oromiya, Ethiopia \\ ${ }^{3}$ School of Medicine, Institute of Health, Jimma University, Jimma, Ethiopia \\ ${ }^{4}$ School Pharmacy, Institute of Health, Jimma University, Jimma, Ethiopia
}

Correspondence should be addressed to Yonas Biratu Terfa; yonibirre@gmail.com

Received 12 May 2021; Revised 20 December 2021; Accepted 15 January 2022; Published 4 February 2022

Academic Editor: Md Nazirul Islam Sarker

Copyright (c) 2022 Yonas Biratu Terfa et al. This is an open access article distributed under the Creative Commons Attribution License, which permits unrestricted use, distribution, and reproduction in any medium, provided the original work is properly cited.

\begin{abstract}
Background. Driving a three-wheel car is an emerging job opportunity in most parts of developing countries. Drivers are at risk for developing low back pain (LBP). However, very little is known about the association between ergonomics factors and LBP among threewheel drivers. Objective. This study was aimed to identify ergonomic risk factors of LBP among three-wheel drivers. Methods. A community-based cross-sectional study on 396 participants was conducted in the Jimma city on all selected public three-wheel drivers in March, 2020. The data were collected using a standard questionnaire adapted from the Nordic Musculoskeletal questionnaire, anthropometric measurements, and observation checklist. The collected data were entered into Epi Data and exported to SPSS version 21.0. Logistic regression analysis was used for analysis based on the p value less than 0.05, 95\% C.I. Results. Among 422 planned respondents, $396(93.8 \%)$ have given the complete response. The mean age of the study population was $27.94( \pm 5.45)$. One hundred four (26.26\%) out of 396 participants had experienced low back pain in the last 12 months. Driving in sitting upright position OR $=0.32(95 \%$ $\mathrm{CI}=0.12-0.86)$, steer wheel handling $\mathrm{OR}=3.02(95 \% \mathrm{CI}=1.58-5.77)$, not holding extra passengers $\mathrm{OR}=0.35(95 \% \mathrm{CI}=0.21,0.60)$, rest breaks, and brand of the three-wheel vehicles were significantly associated with LBP. Conclusion. Nearly more than one-fourth of threewheel drivers in our study had LBP. The finding implies a significant number of three-wheel drivers are at risk of developing reduced well-being. An appropriate health visit, lifestyle modification, and adequate policy should be established in the study area.
\end{abstract}

\section{Introduction}

Work-related low back pain (LBP) is one of the most typical musculoskeletal disorders which affect work performance and the general well-being [1-3]. LBP occurs as a result of muscle tightness beneath the coastal edge and above the lower gluteal pleat $[4,5]$. The occurrences of LBP are very common among workers as probably caused, at least in part, or exacerbated by the job climates $[4,5]$.

Occupational health has been a major cause of worry in the driving profession particularly among three-wheel drivers $[6,7]$. Bajaj is among one of the most important modes of within-city transport system, relatively inexpensive, easily accessible, and an emerging job opportunity in most parts of developing countries [8] (Figure 1).

Globally, 37\% of LBP is due to the occupation [9], and its prevalence is rising from 60 to $70 \%$ with an incidence rate of $5 \%$ [2]. Driving job is often related to the occurrence of LBP due to ergonomic risk factors [10-12]. The prevalence of LBP varies by nation, for example, in USA $81 \%$, Israel $45.4 \%$ [12], Sri Lanka 15.5\% [13], Malaysia 48.5\% [14], Egypt 73.9\% [15], and Ethiopia 65\% [16].

According to research in the field of ergonomics, prolonged sitting, whole-body vibration, the ergonomic mismatch between anthropometric measurements of the drivers, physical environment, lifting or carrying heavy 


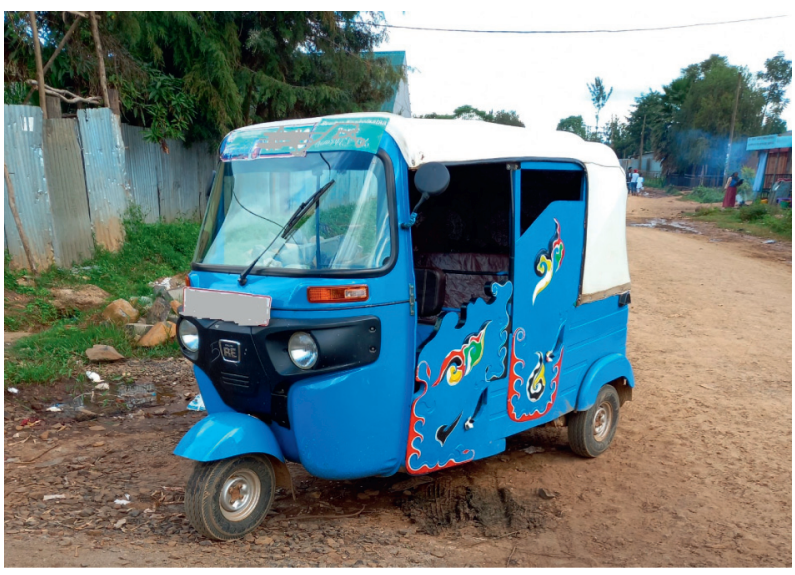

FIgURE 1: Three-wheel car.

objects, and prolonged uncomfortable postures while driving are risk factors for LBP $[17,18]$. The type of vehicle seat as well as occupational risk factors such as long daily working hours, years of driving, and pressure to compete are the main ergonomic risk factors contributing to LBP $[14,19-21]$. However, the extent to which these risk factors are associated with LBP among three-wheel drivers is unknown. Thus, the aim of this study was to identify ergonomic risk factors of LBP among three-wheel drivers in the Jimma city, Ethiopia.

\section{Methods and Materials}

2.1. Study Setting and Design. This community-based crosssectional study was conducted in the Jimma city, Oromia regional state, southwest Ethiopia, from March 01 to March 31, 2020. Jimma city is one of the oldest cities in Ethiopia, and it is located $352 \mathrm{~km}$ southwest from the capital Addis Ababa. Based on data from 2016 of the town administration, it has a total population of 195,443 . The city has 17 kebeles and two woredas. There are a total of 2000 public three wheel cars in the city that act aspublic transport within 12 site stations, and most of the main roads of the city are covered by asphalt.

2.2. Study Population. All four hundred twenty-two selected public three-wheel drivers were our study population. Fulltime three-wheel drivers, with at least six months driving experience, on-duty during data collection time, and willing to participate were included in the study. However, individuals who have known LBP prior to entrance into the profession or having a low back pain of traumatic origin were excluded from the study.

2.3. Sample Size Estimation. The sample size was estimated using a sample size formula for estimating a single population proportion with a margin of error of $5 \%$, confidence interval of $95 \%$, and by considering a $50 \%$ proportion of low back pain among three-wheel drivers because there are no previous data on this study subject. After adding $10 \%$ for the nonresponse rate, our final sample size was 422 .
2.4. Sampling and Data Collection Procedures. The list of three-wheel cars' plate numbers was taken from the city administration with respective terminal sites. Then, threewheel car plates were randomly selected by computergenerated simple random sampling method using ran between approaches on an excel sheet. Proportional allocation of the total sample size to all terminal's sites ( 2 sites $=36$ samples each and 35 samples on the left 10 of the left terminal sites) was done. A total of 422 three-wheel drivers who fulfil inclusion criteria were interviewed. For observational purposes, a nonparticipatory observational approach was used. Finally, the data were collected using an intervieweradministered questionnaire and observation checklist by trained professionals under consideration of WHO prevention for COVID-19 global pandemic such as mask on, social distancing, and utilization of personal protective methods [22].

Data collection was performed by twelve trained BSc nurses and four supervisors of MSc holders in health discipline by following standard procedures. The pilot test was conducted on 21 participants before the actual data collection period.

2.5. Dependent Variable. The dependent variable used in this study was low back pain.

\subsubsection{Independent Variables}

Sociodemographic characteristics: age, level of education, ethnicity, religion, marital status, employment status, and average monthly income

Anthropometric measurements: weight, height, and BMI

Ergonomics factors: seat, sitting posture, back support, steering wheel, number of passengers beside the driver, rest breaks between driving, work experience, working hour per day, working hour per week, and brand of the three-wheel car

Low back pain: pain, muscle tension, or stiffness localized below the costal margin and above the inferior 
gluteal folds, with or without sciatica and is defined as chronic when it persists for 12 weeks or more [23]

Ergonomic risk factors: workplace situations that cause wear and tear on the body and can cause injury [24]

BMI: according to our study, it is categorised as underweight $\left(<18.5 \mathrm{~kg} / \mathrm{m}^{2}\right)$, normal $\left(18.5-24.9 \mathrm{~kg} / \mathrm{m}^{2}\right)$, overweight $\left(25-29.9 \mathrm{~kg} / \mathrm{m}^{2}\right)$, and obese $\left(\geq 30 \mathrm{~kg} / \mathrm{m}^{2}\right)$ [25]

2.6. Data Collection Tool. Data were collected using a standard questionnaire adapted from the Nordic Musculoskeletal Questionnaire (NMQ) and used in different languages in many parts of the world. The NMQ tool's answer confidence ranges from 0 to $23 \%$. Validity tested against clinical history and NMQ found a range of 0 to $20 \%$ disagreement [26]. The tool has three domains: domain I sociodemographic characteristics, domain II anthropometric measurements, and domain III Nordic musculoskeletal questions, which contains 7,4 , and 10 items, respectively. Six items of the observational checklist were also used.

After completing the interview, anthropometric measurements (height and weight) were collected. The body weight was measured to the nearest $0.1 \mathrm{~kg}$ with a digital weighing scale. The body height was also measured using a steel measuring tape meter to the nearest $0.1 \mathrm{~cm}$ from the participant's head to toe in an upright standing position.

2.7. Data Analysis Method. Data were analysed using SPSS, version 21.0. Continuous variables were reported as means and standard deviations and categorical variables as counts and percentages.

However, binary logistic regression analysis was used to identify candidate variables, and variables that reached a $p$ value $<0.25$ in the bivariate analysis were entered into the multivariate logistic analysis and the independent predictors of the prevalence of low back pain were estimated considering the $p$ value less than $0.05,95 \%$ CI.

\section{Results}

3.1. Individual Characteristics of the Participants. A total of 422 drivers were approached, and 396 have given the complete response with $93.84 \%$ of response rate. All the study participants were male with different background characteristics. The majority of the participants were young, found in the age range of $21-30$ years (64\%) with a mean age of 27.94 $( \pm 5.45)$. Nearly three-fourth of the respondents completed the secondary school. About 141 (35.1\%) and 255 (64.4\%) of respondents were from Orthodox religion and Oromo ethnicity, respectively. Nearly less than one half of the respondents earn between 1500 and 3000 Ethiopian birr per month while a small number 17 (4.3\%) earn more than 6000 Ethiopian birr monthly income. Regarding the employment status, more than half of the respondents drive their private three-wheel car and others were employed by the owner of the three-wheel car. More than four-fifth $(82.8 \%)$ of the respondents' BMIs were ranged between 18.5 and $24.99 \mathrm{~kg} / \mathrm{m}^{2}$ which is considered as a normal range (Table 1).
3.2. Ergonomic Risk Factors and LBP. One hundred four (26.26\%) out of 396 participants experienced low back pain within the last 12 months. The three-wheel drivers in the Jimma city reported several ergonomic risk factors such as, uncomfortable seat, sitting posture, back support, and steering wheel with the number of respondents being 118 $(29.8 \%), 136(34.3 \%), 148(37.4 \%)$, and $94(23.7 \%)$, respectively, for LBP (Table 2). This result is supported by an observational checklist in which most of the drivers were sitting in an incline position while driving and uncomfortable with steering wheel handling specially when they had held the passenger beside their seat.

However, the finding showed contradictory findings on what aggravates and relieves LBP among those who reported LBP in the last 12 months. While some study subjects reported a sitting position $56(53.8 \%)$, prolonged standing 53 (50.9\%), walking $13(3.3 \%)$, side sleep 11 (2.8\%), and backward laydown 10 (2.5\%) aggravates LBP, on the contrary, the other respondents reported layback ward, side sleep, walking, and sitting with 47 (45.2\%), 38 (36.5\%), 32 (30.7\%), and $12(11.5 \%)$, respectively as relieving factors for LBP (Table 3).

As described in Table 4, comfortable sitting posture, comfortable steering wheel, number of passengers beside the driver, rest breaks between driving, and brand of the threewheel showed statistically significant association with LBP. Respondents who had comfortable sitting postures were $68 \%$ $\mathrm{OR}=0.32$ [95\% CI $0.12-0.86$ ] less likely to develop lower back pain than those who reported uncomfortable sitting posture. Respondents who had no comfortable steer wheel handling were 3 times $\mathrm{OR}=3.02$ [95\% CI $=1.58$, 5.77] more likely to experience LBP than respondents who reported their steer wheel handling is comfortable.

Regarding the number of passengers beside the driver, respondents who did not hold passengers beside their seat mostly were $65 \% \mathrm{OR}=0.35,[95 \% \mathrm{CI}=0.21,0.60]$ more likely to develop low back pain than respondents who were holding passengers beside their seat. Respondents who had a taken a break between driving for less than 15 minutes and 15 minutes and more were less likely to develop LBP than respondents who had not a break between driving $\mathrm{OR}=0.45$ $[95 \% \mathrm{CI}=0.21,0.94]$ and $\mathrm{OR}=0.31 \quad[95 \% \mathrm{CI}=0.12,0.79]$, respectively. Respondents who were driving brand 2 and brand 4 of the three-wheel car were more likely to develop lower back pain than respondents who were driving brand 5 $\mathrm{OR}=10.19[95 \% \mathrm{CI}=0.91,113.62]$ and $\mathrm{OR}=9.37[95 \%$ $\mathrm{CI}=1.13,77.63]$, respectively (Table 4 ).

\section{Discussion}

This study investigated the association between work-related ergonomic risk factors and LBP among three-wheel drivers in the Jimma city, southwest Ethiopia. The finding showed that $26.26 \%$ of the three-wheel drivers experienced LBP in the last 12 months. This may indicate driving three-wheel car subjects the individual to the tightness of the muscle beneath the coastal edge and lower gluteal pleat $[4,5]$. Other studies have also reported the episodes of LBP are high in such working environments [10-12]. 
TABLE 1: Sociodemographic characteristics among three-wheel drivers in the Jimma city, southwest Ethiopia, 2020.

\begin{tabular}{|c|c|c|}
\hline Variable & Frequency & Percentage \\
\hline \multicolumn{3}{|l|}{ Age (in years) } \\
\hline Less than 20 & 30 & 7.6 \\
\hline $20-30$ & 254 & 64.1 \\
\hline $31-40$ & 102 & 25.8 \\
\hline$\geq 41$ & 10 & 2.5 \\
\hline \multicolumn{3}{|l|}{ Educational level } \\
\hline Primary school & 60 & 15.2 \\
\hline Secondary school & 261 & 65.9 \\
\hline College and above & 75 & 18.9 \\
\hline \multicolumn{3}{|l|}{ Marital status } \\
\hline Single & 227 & 57.3 \\
\hline Married & 163 & 41.2 \\
\hline Widowed & 6 & 1.5 \\
\hline \multicolumn{3}{|l|}{ Religion } \\
\hline Muslim & 130 & 32.8 \\
\hline Orthodox & 141 & 35.6 \\
\hline Protestant & 125 & 31.6 \\
\hline \multicolumn{3}{|l|}{ Ethnicity } \\
\hline Oromo & 255 & 64.4 \\
\hline Amhara & 46 & 11.6 \\
\hline Kefa & 39 & 9.8 \\
\hline Yem & 17 & 4.3 \\
\hline Dewaro & 18 & 4.5 \\
\hline Gurage & 10 & 2.5 \\
\hline Wolayita & 11 & 2.8 \\
\hline \multicolumn{3}{|c|}{ Average monthly income (Ethiopian birr) } \\
\hline$<1500$ & 51 & 12.9 \\
\hline $1500-3000$ & 182 & 46.0 \\
\hline $3001-6000$ & 146 & 36.9 \\
\hline$>6000$ & 17 & 4.3 \\
\hline \multicolumn{3}{|c|}{ Body mass index $\left(\mathrm{kg} / \mathrm{m}^{2}\right)$} \\
\hline$<18.5$ & 28 & 7.1 \\
\hline $18.5-24.99$ & 328 & 82.8 \\
\hline $25-29.99$ & 36 & 9.1 \\
\hline$\geq 30$ & 4 & 1.0 \\
\hline \multicolumn{3}{|l|}{ Car ownership } \\
\hline Owner & 207 & 52.3 \\
\hline Employee & 189 & 47.7 \\
\hline
\end{tabular}

TABLE 2: Ergonomic risk factors related to the car among three-wheel drivers.

\begin{tabular}{lcc}
\hline Variable & Frequency & Percentage \\
\hline Comfort seat & 118 & 29.8 \\
No & 278 & 70.2 \\
Yes & & 34.3 \\
Comfortable sitting postures & 136 & 65.7 \\
No & 260 & \\
Yes & 148 \\
Comfortable back support & 248 \\
No & & 37.4 \\
Yes & 94 \\
Comfortable steering wheel & 302 & 62.6 \\
No & & 23.7 \\
Yes & 290 \\
No & 106 & 76.3 \\
Yes & & 73.2 \\
Brand of the three-wheel car & 230 \\
Brand 1 & & 26.8 \\
\hline
\end{tabular}


TABLE 2: Continued.

\begin{tabular}{lcc}
\hline Variable & Frequency & Percentage \\
\hline Brand 2 & 13 & 3.3 \\
Brand 3 & 6 & 1.5 \\
Brand 4 & 133 & 33.6 \\
Brand 5 & 48 & 12.1 \\
\hline
\end{tabular}

TABLE 3: Work-related risk factors among three-wheel drivers.

\begin{tabular}{|c|c|c|}
\hline Variable & Frequency & Percentage \\
\hline \multicolumn{3}{|l|}{ Work experience } \\
\hline Less than 5 years & 356 & 89.9 \\
\hline Five year and more & 40 & 10.1 \\
\hline \multicolumn{3}{|l|}{ Daily working hours } \\
\hline 8 hours and less than 8 & 141 & 35.6 \\
\hline More than eight hours & 255 & 64.4 \\
\hline \multicolumn{3}{|l|}{ Working days per week } \\
\hline 5 and less than 5 days & 14 & 3.5 \\
\hline More than five days & 382 & 96.5 \\
\hline \multicolumn{3}{|l|}{ Rest breaks between driving } \\
\hline None & 48 & 12.1 \\
\hline Less than 15 minutes & 67 & 16.9 \\
\hline$\geq 15$ minutes & 281 & 71.0 \\
\hline \multicolumn{3}{|l|}{ Age (in years) } \\
\hline Less than 20 & 30 & 7.6 \\
\hline $20-30$ & 254 & 64.1 \\
\hline $31-40$ & 102 & 25.8 \\
\hline$\geq 41$ & 10 & 2.5 \\
\hline \multicolumn{3}{|l|}{ Educational level } \\
\hline Primary school & 60 & 15.2 \\
\hline Secondary school & 261 & 65.9 \\
\hline College and above & 75 & 18.9 \\
\hline
\end{tabular}

TABLE 4: Bivariate and multivariate logistic regression model showing ergonomic predictors of LBP among three-wheel drivers.

\begin{tabular}{|c|c|c|}
\hline Variables & $\mathrm{COR} / 95 \% \mathrm{CI} / P$ value & $\mathrm{AOR} / 95 \% \mathrm{CI} / P$ value \\
\hline \multicolumn{3}{|l|}{ Comfort seat } \\
\hline No & $0.61(0.36,1.04) / 0.07^{*}$ & $1.29(0.48,3.46) 0.60$ \\
\hline Yes & 1 & 1 \\
\hline \multicolumn{3}{|l|}{ Comfortable sitting postures } \\
\hline Yes & $0.52(0.32,0.90) 0.01^{*}$ & $0.32(0.12,0.86) 0.02^{* *}$ \\
\hline No & 1 & 1 \\
\hline \multicolumn{3}{|l|}{ Comfortable back support } \\
\hline No & $0.86(0.54,1.38) 0.55$ & \\
\hline Yes & 1 & \\
\hline \multicolumn{3}{|l|}{ Comfortable steering wheel } \\
\hline No & $1.47(0.88,2.44) 0.13^{*}$ & $3.02(1.58,5.77) 0.00^{* *}$ \\
\hline Yes & 1 & 1 \\
\hline \multicolumn{3}{|c|}{ Do you hold passengers beside you mostly? } \\
\hline No & $0.43(0.26,0.69) 0.00^{*}$ & $0.35(0.21,0.60) 0.00^{* *}$ \\
\hline Yes & 1 & 1 \\
\hline \multicolumn{3}{|l|}{ Work duration by year } \\
\hline Less than 5 years & $0.43(0.22,0.84) 0.01^{*}$ & $0.56(0.27,1.19) 0.13$ \\
\hline Five year and more & 1 & 1 \\
\hline \multicolumn{3}{|l|}{ Daily working hours } \\
\hline 8 hours and less than 8 & $0.76(0.47,1.22) 0.26$ & \\
\hline More than eight hours & 1 & \\
\hline \multicolumn{3}{|l|}{ Working days per week } \\
\hline 5 and less than 5 days & $0.46(0.10,2.10) 0.32$ & \\
\hline
\end{tabular}


TABLE 4: Continued.

\begin{tabular}{lcc}
\hline Variables & COR/95\% CI/P value & AOR/95\% CI/P value \\
\hline $\begin{array}{l}\text { More than five days } \\
\text { Rest breaks between driving }\end{array}$ & 1 & 1 \\
None & 1 & $0.45(0.21,0.94) 0.03^{* *}$ \\
Less than 15 minutes & $0.44(0.22,0.89) 0.02^{*}$ & $0.31(0.12,0.79) 0.01^{* *}$ \\
15 minutes and more & $0.32(0.13,0.79) 0.01^{*}$ & \\
Brand of the three-wheel car & & \\
Brand 1 & $4.38(0.56,34.2) / 0.16^{*}$ & $6.45(0.78,53.05) 0.08$ \\
Brand 2 & $8.12(0.79,82.7) 0.07^{*}$ & $10.19(0.91,113.62) 0.05^{* *}$ \\
Brand 3 & $0.00(0.00) / 0.99$ & $0.00(0.00) 0.99$ \\
Brand 4 & $5.99(0.68,42.65) / 0.11^{*}$ & $9.37(1.13,77.63) / 0.03^{* *}$ \\
Brand 5 & 1 & 1 \\
\hline
\end{tabular}

* Significant at $P$ value $\leq 0.25$; ** significant at $P$ value $\leq 0.05$.

The current study identified that uncomfortable sitting postures, steering wheel handling, number of passengers beside the driver, rest breaks between driving, and brand of the three-wheel car as significant risk factors for experiencing LBP among three-wheel drivers. These findings are in line with reports from prior studies [14, 19-21]. This indicates that the work environment exposed them to the ergonomic risk factors which in turn risked them to LBP.

This finding shows that drivers who reported comfortable seat posture were 68 times less likely to develop low back pain than respondents who had an uncomfortable sitting posture. This finding is similar to studies conducted in Malaysia [19] and Ethiopia [16]. The current findings also revealed that respondents who had taken a break between driving were less likely to develop LBP than respondents who had not taken a break between driving. This finding is similar to studies from Israel [5] and Ethiopia [20].

Furthermore, respondents who complained of uncomfortable steer wheel handling were 3 times more likely to develop LBP than respondents who did not report uncomfortable steer wheel handling. This is comparable with a study conducted in Egypt [15] in which drivers who complained of uncomfortable steering wheels revealed a high prevalence of lower back pain.

4.1. Strengths and Limitations. The main strengths of this study are that we used a nonparticipatory observation checklist of records as confirmatory for self-reported ergonomic risk factors for LBP. Moreover, this study gives attention to the occupation-related health problem of threewheel drivers which was neglected by the health care workers and researchers. In addition, the data collection was performed under consideration of WHO prevention for COVID-19 global pandemic.

However, the limitations of this study include, like any observational study, the analysis might only identify the associations between exposure to risk factors and LBP but not fix the causality. The twelve months work-related lower back pain prevalence may be under or overestimated due to recall bias. Therefore, the recall bias might be another weakness of the study. Thus, for future, we recommend a longitudinal study for better outcome in all dimensions of pain assessment. This study was conducted in only one part of southwest of Ethiopia which may not show a more comprehensive result representing three-wheel drivers working in Ethiopia.

\section{Conclusion}

This finding shows that nearly more than one-fourth of three-wheel drivers of the Jimma city had low back pain. Some ergonomic risk factors such as uncomfortable sitting postures, steer wheel handling, number of passengers beside the driver, rest breaks between driving, and brand of the three-wheel car are significantly associated with LBP among three-wheel drivers. The finding implies a significant number of three-wheel drivers are at risk of developing reduced well-being. An appropriate health visit, lifestyle modification, and adequate policy brief that addresses this high burden occupation-related problem should be established in the study area.

\section{Data Availability}

The data that support the findings of this study are available upon request from the corresponding author, Yonas Biratu. The data are not publicly available due to their containing information that could compromise the privacy of research participants.

\section{Ethical Approval}

Ethical approval was obtained from the Institutional Review Board of Jimma University (IHRPEJ/566/2020). Participants were informed that their participation is voluntary, and the choice to participate or not would have no any kind of effect on them. All the data obtained in the due course were guaranteed confidentiality by excluding names or any other personal identifiers from the data collection sheet. The identifiers of each eligible subject were replaced by a code, and no master code exists that allows the research data to be linked with the identifiers.

\section{Consent}

Not applicable. 


\section{Conflicts of Interest}

The authors strongly clarify that they have no any financial and nonfinancial competing interests among themselves and with other bodies.

\section{Authors' Contributions}

All authors made substantial contributions to the conception and design, acquisition of data, or analysis and interpretation of data; took part in drafting the article or revising it critically for important intellectual content; gave final approval of the version to be published; and agree to be accountable for all aspects of the work.

\section{Acknowledgments}

The authors thank the drivers of three-wheelers who took part in this study and the data collectors. The authors also want to thank Mr. Vinod Bagilkar for his support on English proofreading. This work was supported by funding from the Jimma University, Institute of Health, Research and Postgraduate Office (IHRPEJ/566/2020); however, it does not include the publication fee process.

\section{References}

[1] W. Panduwinata, "Peranan magnetic resonance imaging dalam diagnosis nyeri punggung bawah kronik," CDK-215, vol. 41, no. 4, 2014.

[2] B. Duthey, Background Paper 6.21 Hearing Loss, WHO Int., Geneva, Switzerland, 2013.

[3] M. S. Z. Alanzi, A. G. A. Almuhawwis, N. M. Abo El-Fetoh, M. A. M. Almalki, T. M. A. Alenezi, and F. M. M. Alruwaili, "Low back pain in population of arar city, northern Saudi arabia: an epidemiological study," The Egyptian Journal of Hospital Medicine, vol. 69, no. 7, pp. 2839-2845, 2017.

[4] M. B. Swift, D. C. Cole, D. E. Beaton, and M. Manno, "Health care utilization and workplace interventions for neck and upper limb problems among newspaper workers," Journal of Occupational and Environmental Medicine, vol. 43, no. 3, pp. 265-275, 2001.

[5] D. Debbarma and S. Mitra, "Occupational health problems of the auto rickshaws service providers in Agartala city: a case study of Nagerjala motor stand," International Journal of Current Research and Review (IJCRR), vol. 9, no. 22, p. 16, 2017.

[6] M. Bilban, "Coaching Za Več Zdravja in Dobrega Počutja Zaposlenih V Zbornik Prispevkov 5 Konference Kariernih Coachev," 2014.

[7] F. Kresal, T. Bertoncel, and M. Meško, "Psychosocial factors in the development of low back pain among professional drivers," Organizacija, vol. 50, no. 2, pp. 151-162, 2017.

[8] L. Punnett, A. Prüss-Ütün, D. I. Nelson et al., "Estimating the global burden of low back pain attributable to combined occupational exposures," American Journal of Industrial Medicine, vol. 48, no. 6, pp. 459-469, 2005.

[9] M. L. Magnusson, M. H. Pope, D. G. Wilder, and B. Areskoug, "Are occupational drivers at an increased risk for developing musculoskeletal disorders?” Spine, vol. 21, no. 6, pp. 710-717, 1996.

[10] C. T. J. Hulshof, J. H. Verbeek, I. Braam, M. Bovenzi, and F. Van Dijk, "Evaluation of an occupational health intervention programme on whole-body vibration in forklift truck drivers: a controlled trial," Occupational and Environmental Medicine, vol. 63, no. 7, pp. 461-468, 2006.

[11] Y.-M. Kim and S.-i. Cho, "Work-life imbalance and musculoskeletal disorders among south Korean workers," International Journal of Environmental Research and Public Health, vol. 14, no. 11, p. 1331, 2017.

[12] D. Alperovitch-Najenson, Y. Santo, Y. Masharawi, M. KatzLeurer, D. Ushvaev, and L. Kalichman, "Low back pain among professional bus drivers: ergonomic and occupational-psychosocial risk factors," Schweizer Archiv Fuer Tierheilkunde, vol. 2, p. 18, 2010.

[13] M. Noda, R. Malhotra, V. DeSilva et al., "Occupational risk factors for low back pain among drivers of three-wheelers in Sri Lanka," International Journal of Occupational and Environmental Health, vol. 21, no. 3, pp. 216-224, 2015.

[14] S. A. R. AL-Dubai, A. M. Qureshi, N. H. Ismail, and K. G. Rampal, "Prevalence and determinants of low back pain among taxi drivers in Malaysia. A cross sectional study," Journal of Advanced Microscopy Research, vol. 2, no. 4, pp. 129-143, 2012.

[15] S. Hakim and A. Mohsen, "Work-related and ergonomic risk factors associated with low back pain among bus drivers," Journal of the Egyptian Public Health Association, vol. 92, no. 3, pp. 195-201, 2017.

[16] T. Yosef, A. Belachew, and Y. Tefera, "Magnitude and contributing factors of low back pain among long distance truck drivers at Modjo dry port, Ethiopia: a cross-sectional study," Journal of Environmental and Public Health, vol. 2019, Article ID 6793090, 7 pages, 2019.

[17] R. Anderson, "The back pain of bus drivers," Spine, vol. 17, no. 12, pp. 1481-1488, 1992.

[18] B. N. Nahar, G. Ashan, and N. A. Khan, "Prevalence of low back pain and associated risk factors among professional car drivers in Dhaka city, Bangladesh," South East Asia Journal of Public Health, vol. 2, no. 1, pp. 60-63, 2012.

[19] M. Fadhli, N. Humairah, N. Khairul, M. Kaswandi, and Z. Junaidah, "Ergonomic risk factors and prevalence of low back pain among bus drivers austin," Austin Journal of Musculoskeletal Disorders, vol. 3, no. 1, p. 1028, 2016.

[20] M. E. Wanamo, S. W. Abaya, and A. B. Aschalew, "Prevalence and risk factors for low back pain (LBP) among taxi drivers in Addis Ababa, Ethiopia: a community based cross-sectional study," The Ethiopian Journal of Health Development, vol. 31, no. 4, pp. 244-250, 2017.

[21] I. Blanco-Montenegro, R. De Ritis, and M. Chiappini, "Imaging and modelling the subsurface structure of volcanic calderas with high-resolution aeromagnetic data at Vulcano (Aeolian Islands, Italy)," Bulletin of Volcanology, vol. 69, no. 6, pp. 643-659, 2007.

[22] WHO, COVID-19 Strategy Update, WHO, Geneva, Switzerland, 2020.

[23] R. Chou, "Low back pain (chronic)," Clinical Evidence Handbook A Publication of BMJ Publishing Group, BMJ Publishing Group, London, UK, 2011, http://www.aafp.org/ afp/bmj.

[24] R. Chou, A. Qaseem, V. Snow et al., "Diagnosis and treatment of low back pain: a joint clinical practice guideline from the American College of Physicians and the American Pain Society," Annals of Internal Medicine, vol. 147, no. 7, pp. 478-491, 2007.

[25] WHO, Body Mass Index-BMI, https://www.euro.who.int/ en/health-topics/disease-prevention/nutrition/a-healthylifestyle/body-mass-index-bmi.

[26] J. O. Crawford, "The nordic musculoskeletal questionnaire," Occupational Medicine, vol. 57, no. 4, pp. 300-301, 2007. 